\title{
Thank you, Guy
}

\author{
Rüdiger von Kummer ${ }^{1}$
}

(C) Springer-Verlag Berlin Heidelberg 2016

As of December 31, 2016, Prof. Dr. em. Guido Wilms completed his term as Editor-in-Chief of this Journal. When Guy became Editor-in-Chief in 2011, Neuroradiology had a 5-year Impact Factor (IF) of 2.556 and an acceptance rate of 37\%. The time from submission to first decision was 35 days, and the time from acceptance to online publication was 25 days. Guy Wilms, together with his Section editors, reduced the time from submission to first decision to 29 days, and the time from acceptance to online publication was reduced to 15 days - due to an improved automated production workflow - making Neuroradiology one of the fastest publishing scientific journals. The 5-year IF increased to 2.829 in 2012, but declined to 2.459 in 2015 , despite a reduction of the acceptance rate to $24 \%$. In 2013, the ESNR-Springer Award was introduced. Since 2016, two prizes have been annually awarded to the two most cited papers in Diagnostic and Interventional Neuroradiology published in Neuroradiology.
Thank you, Guy, for these achievements during the last 6 years as you made Neuroradiology the primary reference not only for European neuroradiologists, but globally as well. Currently, Neuroradiology publishes manuscripts from all over the world: $49 \%$ from Europe, 24\% from North and Latin America, 26\% from Australasia and 0.5\% from Africa. Importantly, our readership is even more equally spread around the world.

It is both a challenge and great honor to take over the position of the Editor-in-Chief. Together with the Section Editors, I aim to increase the impact of Neuroradiology by providing quick and sound peer reviews and publishing the best scientific papers in the field of Diagnostic and Interventional Neuroradiology.

Prof. Dr. med. Rüdiger von Kummer, Senior Professor Editor-in-Chief

Rüdiger von Kummer

Ruediger.vonKummer@uniklinikum-dresden.de

Institute of Diagnostic and Interventional Neuroradiology,

Universitätsklinikum, Dresden, Germany 